\title{
Correction to: Ortho-silicic Acid Inhibits RANKL-Induced Osteoclastogenesis and Reverses Ovariectomy-Induced Bone Loss In Vivo
}

\author{
Wenzheng Ma ${ }^{1} \cdot$ Fu'an Wang $^{1} \cdot$ Yunhao You ${ }^{1} \cdot$ Wenliang Wu ${ }^{1} \cdot$ Hai Chi $^{2} \cdot$ Guangjun Jiao ${ }^{1} \cdot$ Lu Zhang $^{1}$. \\ Hongming $\mathrm{Zhou}^{3} \cdot$ Hongliang Wang ${ }^{1} \cdot$ Yunzhen Chen ${ }^{1}$ (i) \\ Published online: 7 September 2020 \\ (C) Springer Science+Business Media, LLC, part of Springer Nature 2020
}

\section{Correction to: Biological Trace Element Research} https://doi.org/10.1007/s12011-020-02286-6

The original version of this article unfortunately contained a mistake. The name of "Yunzhen Chen" is now corrected in the author group.

The original article has been corrected.

Publisher's Note Springer Nature remains neutral with regard to jurisdictional claims in published maps and institutional affiliations.

The online version of the original article can be found at https://doi.org/ 10.1007/s12011-020-02286-6

\footnotetext{
Yunzhen Chen qilucyz@yeah.net

1 Department of Spine Surgery, Qilu Hospital of Shandong University, Jinan, China

2 Department of traumatic Orthopedics, West Branch of Shandong Provincial Hospital, Jinan, China

3 Department of Spine Surgery, Linyi Central Hospital, Linyi, China
} 